\title{
Targeting glioma cells by antineoplastic activity of reversine
}

\author{
CAMILA HIRAKATA $^{1 *}$, KELI LIMA $^{1 *}$, BRUNA OLIVEIRA DE ALMEIDA ${ }^{1}$, LÍVIA BASSANI LINS DE MIRANDA ${ }^{1}$, \\ KATHARINE GURGEL DIAS FLORÊNCIO ${ }^{2}$, LUCIANA COSTA FURTADO ${ }^{1}$, \\ LETICIA VERAS COSTA-LOTUFO $^{1}$ and JOÃO AGOSTINHO MACHADO-NETO ${ }^{1}$ \\ ${ }^{1}$ Department of Pharmacology, Institute of Biomedical Sciences, University of São Paulo, São Paulo, CEP 05508-900; \\ ${ }^{2}$ Department of Physiology and Pharmacology, Drug Research and Development Center, \\ Federal University of Ceará, Fortaleza, Ceará, CEP 60440-900, Brazil
}

Received April 3, 2021; Accepted June 2, 2021

DOI: 10.3892/ol.2021.12871

\begin{abstract}
Gliomas are the most common type of primary central nervous system tumors and despite great advances in understanding the molecular basis of the disease very few new therapies have been developed. Reversine, a synthetic purine analog, is a multikinase inhibitor that targets aurora kinase A (AURKA) and aurora kinase B (AURKB). In gliomas, a high expression of AURKA or AURKB is associated with a malignant phenotype and a poor prognosis. The present study investigated reversine-related cellular and molecular antiglioma effects in HOG, T98G and U251MG cell lines. Gene and protein expression were assessed by reverse transcription-quantitative PCR and western blotting, respectively. For functional assays, human glioma cell lines (HOG, T98G and $\mathrm{U} 251 \mathrm{MG}$ ) were exposed to increasing concentrations of reversine $(0.4-50 \mu \mathrm{M})$ and subjected to various cellular and molecular assays. Reversine reduced the viability and clonogenicity in a dose- and/or time-dependent manner in all glioma cells, with HOG (high AURKB-expression) and T98G (high AURKA-expression) cells being more sensitive compared with U251MG cells (low AURKA- and AURKB-expression). Notably, HOG cells presented higher levels of polyploidy, while T98G presented multiple mitotic spindles, which is consistent with the main regulatory functions of AURKB and AURKA, respectively. In molecular assays, reversine reduced AURKA and/or AURKB expression/activity and increased DNA damage and apoptosis markers, but autophagy-related proteins were not modulated. In conclusion, reversine potently induced mitotic catastrophe and apoptosis in glioma cells and higher basal levels of aurora kinases and genes responsive to
\end{abstract}

Correspondence to: Professor João Agostinho Machado-Neto, Department of Pharmacology, Institute of Biomedical Sciences, University of São Paulo, 1524 Avenue Professor Lineu Prestes, São Paulo, CEP 05508-900, Brazil

E-mail: jamachadoneto@usp.br

*Contributed equally

Key words: gliomas, glioblastoma, aurora kinases, apoptosis, reversine
DNA damage and may predict improved antiglioma responses to the drug. Reversine may be a potential novel drug in the antineoplastic arsenal against gliomas.

\section{Introduction}

Gliomas are the most common primary central nervous system (CNS) tumors, corresponding to $\sim 80 \%$ of all malignant primary brain tumors in adults (United States of America, 2013-2017) (1). According to the 2016 World Health Organization (WHO) classification of CNS tumors, diffuse gliomas are classified based on histological (astrocytoma, oligoastrocytoma, oligodendroglioma and glioblastoma) and genetic features [isocitrate dehydrogenase mutations, alpha-thalassemia/mental retardation, X-linked (ATRX) loss, TP53 mutation and 1p/19q-codeletion] (2). In addition, the WHO classified CNS tumors into 4 grades (I-IV) that have distinct prognosis and require different therapeutic decisions $(3,4)$. Glioblastomas (grade IV), which correspond to $\sim 50 \%$ of gliomas are highly malignant gliomas with a poor prognosis $(5,6)$. The current therapeutic options for these tumors include surgery, radiation, immunotherapy and chemotherapy with non-specific and highly toxic agents (7-9). Currently, alkylating agents (temozolomide, carmustine and lomustine), mTOR inhibitors (everolimus) and monoclonal antibodies (bevacizumab and naxitamab-gqgk) are approved by the Food and Drug Administration authority for the treatment of high-grade gliomas (https://www.cancer.gov) (10). Inspite of considerable advances in the understanding of the molecular basis of gliomas $(6,11)$, progress in improving the clinical outcomes of the disease is still slow and very few new therapies have been developed.

Reversine [2-(4-morpholinoanilino)-6-cyclohexylaminopurine] is an adenosine triphosphate analog that acts as a potent multi-kinase inhibitor selective to aurora kinases, MPS1 (monopolar spindle 1) and JNK (12-14). The antineoplastic activity of reversine has been demonstrated in hematological and solid tumors, in which it triggered cell cycle arrest, polyploidy, apoptosis and autophagy (15).

Aurora kinases, a family of serine/threonine kinases, consisting of aurora kinase A (AURKA), aurora kinase B (AURKB) and aurora kinase C (AURKC) serve an essential role in cell cycle progression and cellular division (16). High 
expression of AURKA, AURKB and AURKC has observed in several types of cancer, including gliomas and is associated with a poor prognosis (17-19). AURKA and AURKB are members with the most detailed characterizations: AURKA serves a role in the formation of the mitotic spindle during mitosis, while AURKB serves a key role in the organization of the centromere-kinetochore region, microtubule-kinetochore attachments and cytokinesis $(16,20,21)$. Due to the differential expression and biological functions related to the malignant phenotype attributed to these proteins, aurora kinases have been proposed as potential targets for pharmacological intervention, particularly in cancer (22-24).

In gliomas, high AURKA and AURKB expression is associated with a poor prognosis and chemoresistance $(18,25)$, which led to the study of the reversine effects in these disease models. Currently, reversine is in the preclinical phase of study in oncology, but the data accumulated thus far has indicated interesting antineoplastic activity (15). Hence, the identification of the most sensitive type of tumors to reversine, including predictors of response for this drug, may identify a profile of cancer patients eligible for clinical trials. The present study aimed to target aurora kinases using reversine and to identify the cellular and molecular mechanisms underlying its anti-glioma effects.

\section{Materials and methods}

Cell culture, reagents and chemicals. Oligodendroglioma (HOG) and glioblastoma (T98G, U251MG and U87MG) cell lines were kindly provided by Professor Regina Pekelmann Markus (University of São Paulo, São Paulo, Brazil). The authenticity of the cells was determined by Short Tandem Repeat (STR). The STR data from U87MG cells used in the present study is compatible with a glioblastoma of unknown origin (https://web.expasy.org/cellosaurus/CVCL_0022). All cell lines were cultured in the Roswell Park Memorial Institute medium (RPMI)-1640 and supplemented with $10 \%$ fetal bovine serum (FBS), glutamine, $100 \mathrm{U} / \mathrm{ml}$ penicillin, and $100 \mu \mathrm{g} / \mathrm{ml}$ streptomycin. The cells were maintained at $37^{\circ} \mathrm{C}$ in a $5 \% \mathrm{CO}_{2}$ humidified incubator and regularly split to maintain their exponential growth state (up to six passages). Reversine [2-(4-morpholinoanilino)-6-cyclohexylaminopurine] was obtained from Target Molecule Corp. and prepared as a $50 \mathrm{mM}$ stock solution in dimethyl sulfoxide (Me2SO4; DMSO). Z-VAD-FMK was obtained from Cayman Chemical Company and prepared as a $20 \mathrm{mM}$ stock solution in DMSO. Venetoclax (ABT-199) was obtained from Target Molecule Corp. and prepared as a $50 \mathrm{mM}$ stock solution in DMSO. Obatoclax (GX15-070) was obtained from Chemietek and prepared as a $10 \mathrm{mM}$ stock solution in DMSO.

Reverse transcription-quantitative $(R T-q) P C R$. Total RNA was obtained using the TRIzol ${ }^{\circledR}$ reagent (Thermo Fisher Scientific Inc.) from cells according to the manufacturers' protocol. cDNA was synthesized from $1 \mu \mathrm{g}$ of RNA using a High-Capacity cDNA Reverse Transcription kit (Thermo Fisher Scientific Inc.) according to the manufacturers' protocol. qPCR was performed using an ABI 7500 Sequence Detector System (Thermo Fisher Scientific Inc.) in conjunction with a SybrGreen System (Thermo Fisher Scientific
Inc.) for the expression of aurora kinase A (AURKA), aurora kinase B (AURKB), BCL2 apoptosis regulator (BCL2), BCL2 like (BCL2L1 1), baculoviral IAP repeat containing 5 (BIRC5), BCL2 interacting protein 3 (BNIP3), BCL2 interacting protein 3 like (BNIP3L), BCL2 associated agonist of cell death (BAD), BCL2 associated $\mathrm{X}$, apoptosis regulator (BAX), BCL2 binding component 3 (BBC3), phorbol-12-myristate-13-acetate-induced protein 1 (PMAIP1), cyclin dependent kinase inhibitor 1A (CDKN1A), cyclin dependent kinase inhibitor 1B (CDKN1B) and growth arrest and DNA damage inducible alpha (GADD45A) genes (Table SI) according to the manufacturers' protocol. The thermocycling conditions included an initial denaturation at $95^{\circ} \mathrm{C}$ for $10 \mathrm{~min}$, followed by 40 cycles of denaturation $\left(95^{\circ} \mathrm{C}\right.$ for $\left.15 \mathrm{sec}\right)$, annealing $\left(60^{\circ} \mathrm{C}\right.$ for $\left.30 \mathrm{sec}\right)$ and extension $\left(60^{\circ} \mathrm{C}\right.$ for $\left.30 \mathrm{sec}\right)$. Hypoxanthine phosphoribosyltransferase 1 (HPRT1) and $\beta$-actin were used as reference genes. Relative quantification values were calculated using the $2^{-\Delta \Delta \mathrm{Ct}}$ equation (26). A negative 'No Template Control' was included for each primer pair as control for contamination or unspecific amplification. Data were visualized using the multiple experiment viewer (MeV) v.4.9.0 software (27).

Western blotting. Total protein extraction was performed using a buffer containing $100 \mathrm{mM}$ Tris ( $\mathrm{pH} 7.6), 1 \%$ Triton X-100, $150 \mathrm{mM} \mathrm{NaCl}, 2 \mathrm{mM}$ PMSF, $10 \mathrm{mM} \mathrm{Na}_{3} \mathrm{VO}_{4}, 100 \mathrm{mM} \mathrm{NaF}$, $10 \mathrm{mM} \mathrm{Na} \mathrm{P}_{2} \mathrm{O}_{7}$, and $4 \mathrm{mM}$ EDTA from untreated U87MG, HOG, T98G and U251MG cells, or HOG, T98G and U251MG cells treated with vehicle or reversine $(1.6,3.2$ or $6.4 \mu \mathrm{M})$ for $24 \mathrm{~h}$ or for cells treated with $1.6 \mu \mathrm{M}$ reversine for 24,48 and $72 \mathrm{~h}$. Extracted proteins were quantified by the Bradford method. Equal amounts of protein $(30 \mu \mathrm{g})$ were separated by 8-15\% SDS-PAGE (28) and transferred onto nitrocellulose membranes (GE Healthcare). Antibodies against AURKA (cat. no. sc-25425), AURKB (cat. no. sc-25426), phosphorylated (p)-histone $\mathrm{H} 3^{\mathrm{S} 10}$ (sc-8659-R) and p-histone H2A. XS139 ( $\gamma \mathrm{H} 2 \mathrm{AX}$; sc-51748) were purchased from Santa Cruz Biotechnology, Inc. Antibodies against PARP1 (cat. no. 9542), SQSTM1/p62 (cat. no. 88588), LC3BI/II (cat. no. 2775), $\beta$-actin (cat. no. 4970) and $\alpha$-tubulin (cat. no. 2144) were obtained from Cell Signaling Technology, Inc. All primary antibodies were used at 1:1,000 dilution and incubated for $16 \mathrm{~h}$ at $4^{\circ} \mathrm{C}$. $\alpha$-tubulin and $\beta$-actin were used as the loading controls. Secondary antibodies anti-mouse (cat. no. 7076) and anti-rabbit (cat. no. 7074) conjugated with horseradish peroxidase were obtained from Cell Signaling Technology, Inc. and used at 1:2,000 dilution with $2 \mathrm{~h}$ of incubation at room temperature. The SuperSignal ${ }^{\mathrm{TM}}$ West Dura Extended Duration Substrate system (Thermo Fisher Scientific, Inc.) and G:BOX Chemi XX6 gel document system (Syngene Europe) were used for blot visualization. Band intensities were determined using UN-SCAN-IT gel 6.1 software (SilkScientific).

Cell viability assay. Cell viability was determined by a sulforhodamine B (SRB) assay. Briefly, a total of 4x10 3 glioma cells (HOG, T98G and U251MG) per well were seeded in a 96-well plate in an RPMI-1640 medium with $10 \%$ FBS in the presence of vehicle (DMSO) or different concentrations of reversine $(0.4,0.8,1.6,3.1,6.3,12.5,25.0$ and $50.0 \mu \mathrm{M})$ for 24 , 48 and 72 h. Dose-response cytotoxicity for HOG, T98G, and U251MG cells treated with vehicle or graded concentrations 
of venetoclax $(0.1,0.5,1,5,10$ and $50 \mu \mathrm{M})$ or obatoclax $(0.01$, $0.03,0.1,0.3,1$ and $3 \mu \mathrm{M}$ ) for $48 \mathrm{~h}$ was performed. For drug combination studies, HOG, T98G and U251MG cells were treated with vehicle or graded concentrations of reversine $(0.8$, 1.6, 3.2 and $6.4 \mu \mathrm{M})$ in combination or not with Z-VAD-FMK $(20 \mu \mathrm{M})$, venetoclax $(5 \mu \mathrm{M})$, or obatoclax (HOG, $10 \mathrm{nM}$; T98G, $30 \mathrm{nM}$ and U251MG, $100 \mathrm{nM}$ ) for $48 \mathrm{~h}$. The cells were then fixed with $10 \%$ trichloroacetic acid at $4^{\circ} \mathrm{C}$ for at least $1 \mathrm{~h}$. Subsequently, the plates were washed with distilled water three times and a $0.2 \%$ solution of SRB diluted in $1 \%$ acetic acid was added to the plates and incubated for $30 \mathrm{~min}$ at $37^{\circ} \mathrm{C}$. The non-associated dye was removed by washing with $1 \%$ acetic acid three time and the plates were dried at room temperature. Next, the plates were incubated with a $10 \mathrm{mM}$ TRIS pH 10.5 solution under stirring for $30 \mathrm{~min}$ at $4^{\circ} \mathrm{C}$. Cell viability was evaluated by measuring the absorbance at $570 \mathrm{~nm}$. The inhibitory concentration (IC) $)_{50}$ values were calculated by performing a nonlinear regression analysis in GraphPad Prism 5 (GraphPad Software, Inc.).

Clonogenic assay. HOG, T98G and U251MG cells $\left(1 \times 10^{3}\right.$ cells $/ 35 \mathrm{~mm}^{2}$ plate) were incubated with vehicle or different concentrations of reversine $(0.2,0.4,0.8$ and $1.6 \mu \mathrm{M})$ for $24 \mathrm{~h}$ and then the medium was replaced with a drug-free medium (RPMI-1640 with 10\% FBS). Colonies were detected after 10-15 days of culture by adding $0.5 \%$ crystal violet (Sigma-Aldrich; Merck KGaA) to a $10 \%$ ethanol solution for $15 \mathrm{~min}$ at room temperature. Images were acquired using the G:BOX Chemi XRQ (Syngene Europe) and analyzed using ImageJ 1.45s software (US National Institutes of Health).

Cell cycle analysis. A total of $2 \times 10^{5}$ cells/well (HOG, T98G and $\mathrm{U} 251 \mathrm{MG}$ ) were seeded in 6-well plates in the presence of vehicle or reversine $(0.8$ and $1.6 \mu \mathrm{M})$, harvested after $24 \mathrm{~h}$, fixed with $70 \%$ ethanol for at least $2 \mathrm{~h}$ at $4{ }^{\circ} \mathrm{C}$, and stored at $4{ }^{\circ} \mathrm{C}$ for up to 7 days. Fixed cells were stained with $20 \mu \mathrm{g} / \mathrm{ml}$ propidium iodide (PI) containing $10 \mu \mathrm{g} / \mathrm{ml}$ RNase A for $30 \mathrm{~min}$ at room temperature in a light-protected area. DNA content distribution was acquired using a FACSCalibur (Becton-Dickinson) flow cytometer and analyzed using FlowJo software v.X.0.7 (Treestar, Inc.).

Immunofluorescence analysis. HOG, T98G and U251MG cells treated with vehicle or $1.6 \mu \mathrm{M}$ reversine for $24 \mathrm{~h}$, were fixed with ice-cold $100 \%$ methanol, permeabilized with $0.5 \%$ Triton X-100 in PBS for 30 min at room temperature and blocked with $1 \%$ bovine serum albumin (BSA) in PBS for $1 \mathrm{~h}$ at room temperature. Next, the cells were incubated with anti- $\alpha$-tubulin Alexa Fluor ${ }^{\circledR} 488$ conjugate (cat. no. 53-4502-82; 1:200 in 1\% BSA in PBS; Thermo Fisher Scientific Inc.) for $16 \mathrm{~h}$ at $4^{\circ} \mathrm{C}$ protected from light followed by washing once with PBS. Finally, the slides were mounted in ProLong Gold Antifade Mountant with DAPI (Thermo Fisher Scientific Inc.) for $1 \mathrm{~h}$ at room temperature. Images were captured using a fluorescent microscope (Lionheart FX Automated microscope; BioTek Instruments Inc.; magnification, x400).

Trypan blue exclusion. Cell viability was measured using a trypan blue dye (Sigma-Aldrich; Merck KGaA) exclusion test after the incubation of HOG, T98G and U251MG cells $\left(1 \times 10^{5}\right.$ cells $\left./ \mathrm{ml}\right)$ with vehicle or $0.4,1.6$ and $6.4 \mu \mathrm{M}$ of reversine for $72 \mathrm{~h}$. The supernatants $(500 \mu \mathrm{l})$ were collected and the cells were removed after the addition of $100 \mu \mathrm{l}$ of PBS (phosphate buffered saline), $50 \mu \mathrm{l}$ of trypsin and $100 \mu \mathrm{l}$ of RPMI-1640 medium. Each step was performed twice. The cell solution was mixed and an aliquot of $10 \mu 1$ of trypan blue was added to $90 \mu \mathrm{l}$ of the cell solution. Cells of this solution were counted using a light microscope (magnification, x100) and Neubauer chamber (OPTIK-Labor), and cells dyed with trypan blue were considered non-viable cells.

Statistical analysis. Statistical analyses were performed using GraphPad Prism v5 (GraphPad Software, Inc.). For multiple comparisons, ANOVA followed by the post hoc Bonferronis test was used. For the comparison of 2 groups, the paired Student's t-test was used. $\mathrm{P}<0.05$ was considered to indicate a statistically significant difference. The $\mathrm{IC}_{50}$ values were calculated by performing a nonlinear regression analysis in GraphPad Prism v5. Each experiment was repeated three times and data were presented as the means $\pm \mathrm{SD}$.

\section{Results}

AURKA and AURKB expression in glioma cell lines. First, AURKA and AURKB mRNA and protein levels as well histone $\mathrm{H} 3$ phosphorylation were investigated in a panel of glioma cell lines. T98G cells exhibited the highest levels of AURKA mRNA ( $<<0.001$, HOG vs. U87MG or U251MG; $\mathrm{P}<0.05$, T98G vs. U87MG or U251MG) and protein $(\mathrm{P}<0.01$, T98G vs. other cell lines), while HOG cells exhibited the highest levels of AURKB mRNA $(\mathrm{P}<0.001, \mathrm{HOG}$ vs. other cell lines; $\mathrm{P}<0.05$, T98G vs. U87MG) and protein $(\mathrm{P}<0.001$, HOG vs. other cell lines; $\mathrm{P}<0.01$, T98G vs. U87MG cell line) (Fig. 1A-C). U87MG and U251MG cells showed low levels of AURKA and AURKB (Fig. 1A-C). Higher levels of p-histone H3 were observed in T98G cells $(\mathrm{P}<0.01$, T98G vs. other cell lines) (Fig. 1C), indicating increased AURKB activity. Based on these findings, HOG, T98G and U251MG were selected for additional functional assays.

Reversine reduces cell viability and clonogenicity in glioma cells. Next, the effects of reversine on the viability of glioma cells were investigated. Reversine reduced the viability in a dose- and time-dependent manner in all the glioma cell lines, with HOG and T98G cells being more sensitive compared with U251MG cells (Fig. 2A). The 24, 48 and $72 \mathrm{~h} \mathrm{IC}_{50}$ were, respectively, $12,<0.4$ and $<0.4 \mu \mathrm{M}$ for HOG cells; $11,3.6$ and $0.4 \mu \mathrm{M}$ for T98G cells; and 13, 7.5, and $6.9 \mu \mathrm{M}$ for U251MG cells (Fig. 2A). Similar results were observed in the colony formation assay. In HOG and T98G cells, reversine exposure for $24 \mathrm{~h}$ strongly reduced clonogenicity capacity $(>80 \%$ of reduction in colony formation at doses $\geq 0.4 \mu \mathrm{M}$ ), while reversine reduced clonogenicity to a lower degree in U251MG (reduction ranged from 33-48\%) (Fig. 2B and C) compared with vehicle-treated cells. These data suggested that glioma cells expressing higher AURKA or AURKB levels may be more sensitive to the antineoplastic effects of reversine.

Reversine triggers mitotic aberrations and polyploidy in glioma cells. As aurora kinases serve a key role in mitosis 
A

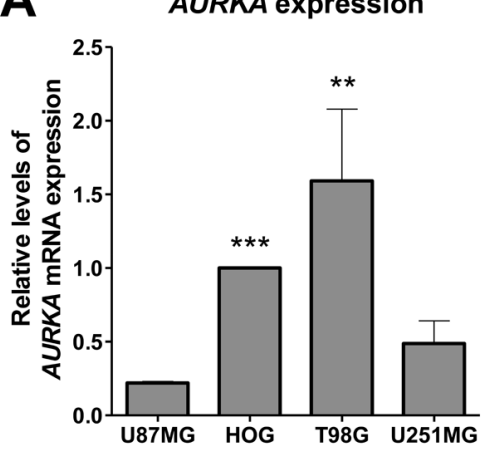

C

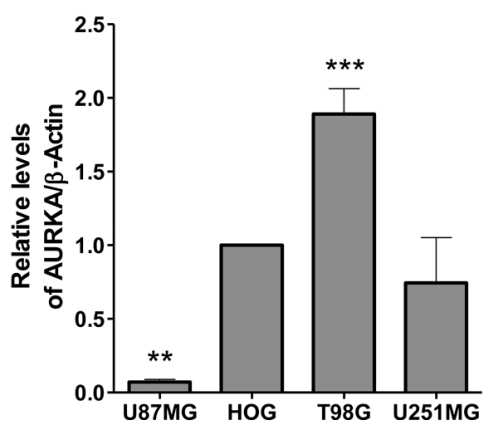

AURKB expression

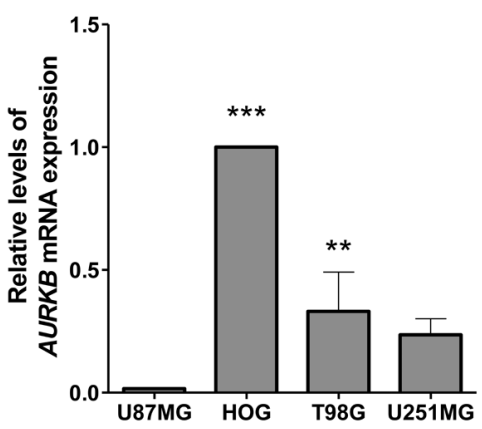

AURKB expression

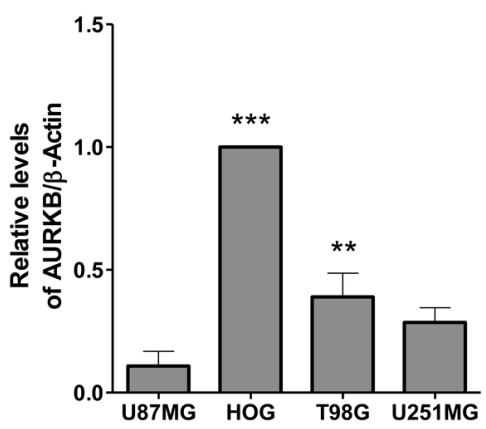

B

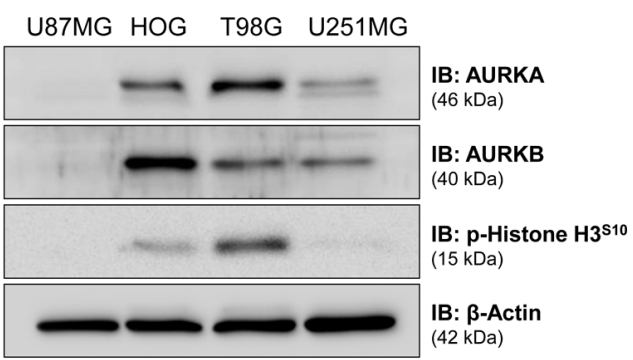

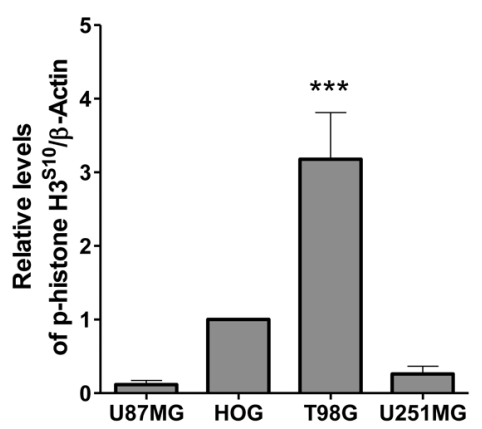

Figure 1. Expression of AURKA and AURKB in glioma cell lines. (A) RT-qPCR analysis of AURKA and AURKB mRNA expression in U87MG, HOG, T98G and U251MG cells. Bar graphs represent the mean \pm SD of at least 3 independent samples. AURKA expression analysis: ${ }^{* * *} \mathrm{P}<0.001, \mathrm{HOG}$ vs. U87MG or U251MG; ** P $<0.05$, T98G vs. U87MG or U251MG. AURKB expression analysis: ${ }^{* * *} \mathrm{P}<0.001$, HOG vs. other cell lines; * $\mathrm{P}<0.05$, T98G vs. U87MG. (B) Western blot analysis for AURKA, AURKB and p-histone H3 ${ }^{S 10}$ in total cell extracts from U87MG, HOG, T98G, and U251MG; membranes were reprobed with the antibody for the detection of $\beta$-actin. (C) Bar graphs represent the mean \pm SD of 3 independent experiments quantifying band intensities of indicated proteins. AURKA protein levels: ${ }^{* * *} \mathrm{P}<0.01$, T98G vs. other cell lines; ${ }^{* * *} \mathrm{P}<0.01$, U87MG vs. other cell lines. AURKB protein levels: ${ }^{* * * *} \mathrm{P}<0.001, \mathrm{HOG}$ vs. other cell lines; ${ }^{* *} \mathrm{P}<0.01$, T98G vs. U87MG cell line. Phosphorylated-histone $\mathrm{H} 3{ }^{\mathrm{s} 10}$ levels: ${ }^{* * *} \mathrm{P}<0.01$, T98G vs. other cell lines. ANOVA test and Bonferroni post-test. AURKA, aurora kinase A; AURKB, aurora kinase B; p, phosphorylated; RT-q, reverse transcription-quantitative.

and cytokinesis (16), the impact of reversine on cell cycle progression was investigated. In HOG and T98G cells, reversine treatment reduced S-phase cells and induced polyploidy in a dose-dependent manner $(\mathrm{P}<0.05)$, which was more evident for HOG cells (Fig. 3A). In U251MG cells, treatment with reversine increased $\mathrm{G}_{2} / \mathrm{M}$ arrest and polyploidy in a dose-dependent manner ( $\mathrm{P}<0.05$; Fig. 3A). In T98G and U251MG cells, reversine exposure increased the sub- $\mathrm{G}_{1}$ cell population $(\mathrm{P}<0.05$; Fig. 3A). The morphological analysis via immunofluorescence corroborated the flow cytometry quantitative data and revealed additional qualitative details. An increased frequency of polyploidy cells was observed in reversine-treated HOG cells (Fig. 3B). In T98G cells, mitotic aberrations, including cells with multiple mitotic spindles were observed with reversine treatment (Fig. 3B). Few changes were observed in U251MG cells exposed to reversine, which was consistent with the lower frequency of changes observed by flow cytometry and the lower sensitivity of this cell line to reversine (Fig. 3B) compared with vehicle-treated cells.

Apoptosis and DNA damage markers are induced by reversine exposure in glioma cells. Next, the effect of reversine on cell signaling was investigated, particularly aurora kinase activity, DNA damage, apoptosis and autophagy using western blotting and RT-qPCR. Reversine reduced AURKA and/or AURKB expression/activity and increased $\gamma \mathrm{H} 2 \mathrm{AX}$ and
cleaved-PARP1 (Fig. 4A and B). No consistent modulation in autophagy markers, LC3B, or SQSTM1/p62 were observed in the glioma cells (Fig. 4A and B). These results suggested that a mitotic catastrophe followed by apoptosis may be the main mechanism involved in the reduction of cell viability induced by reversine in glioma cells. To obtain additional insights into the differences in sensitivity to reversine observed among the glioma cell lines, a panel of antiapoptotic, pro-apoptotic and DNA damage-induced cell cycle arrest-related genes was investigated in HOG cells with $1.6 \mu \mathrm{M}$ reversine exposure for $24 \mathrm{~h}$ (Fig. 4C). Based on the gene expression profile, PMAIP1, CDKN1A and GADD45A genes were selected for further investigation in all glioma cells by RT-qPCR. In HOG cells, PMAIP1, CDKN1A and GADD45A genes were significantly upregulated (all $\mathrm{P}<0.01$ ), while only $G A D D 45 \mathrm{~A}$ was significantly upregulated in T98G cells $(\mathrm{P}<0.01$; Fig. 4C) compared with vehicle-treated cells. None of the 3 selected genes was modulated in U251MG cells (Fig. 4C). It is notable that U251MG cells present a homozygous deletion of CDKN1A (29), which is consistent with the absence of amplification of this gene in the present study (Fig. 4C). The trypan blue exclusion assay and PARP1 cleavage corroborated the molecular findings, indicating an increase in cell death with reversine exposure, as observed by increased proportion of cells dyed with trypan blue and the ratio of cleaved-PARP1 (all $\mathrm{P}<0.05$; Figs. 4D and S1). 
A

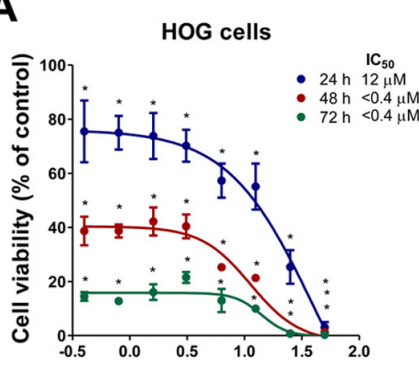

log [Reversine $(\mu \mathrm{M})]$

T98G cells

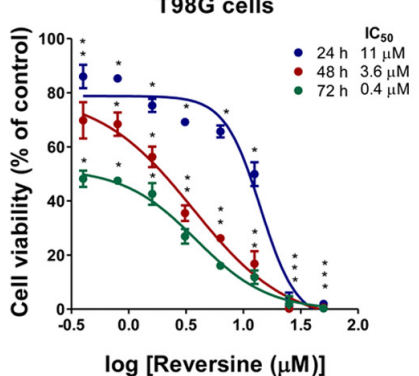

log [Reversine $(\mu \mathrm{M})]$

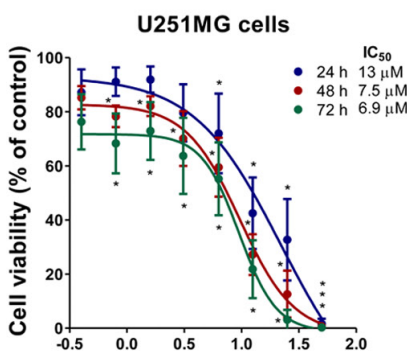

$\log$ [Reversine $(\mu \mathrm{M})]$
B

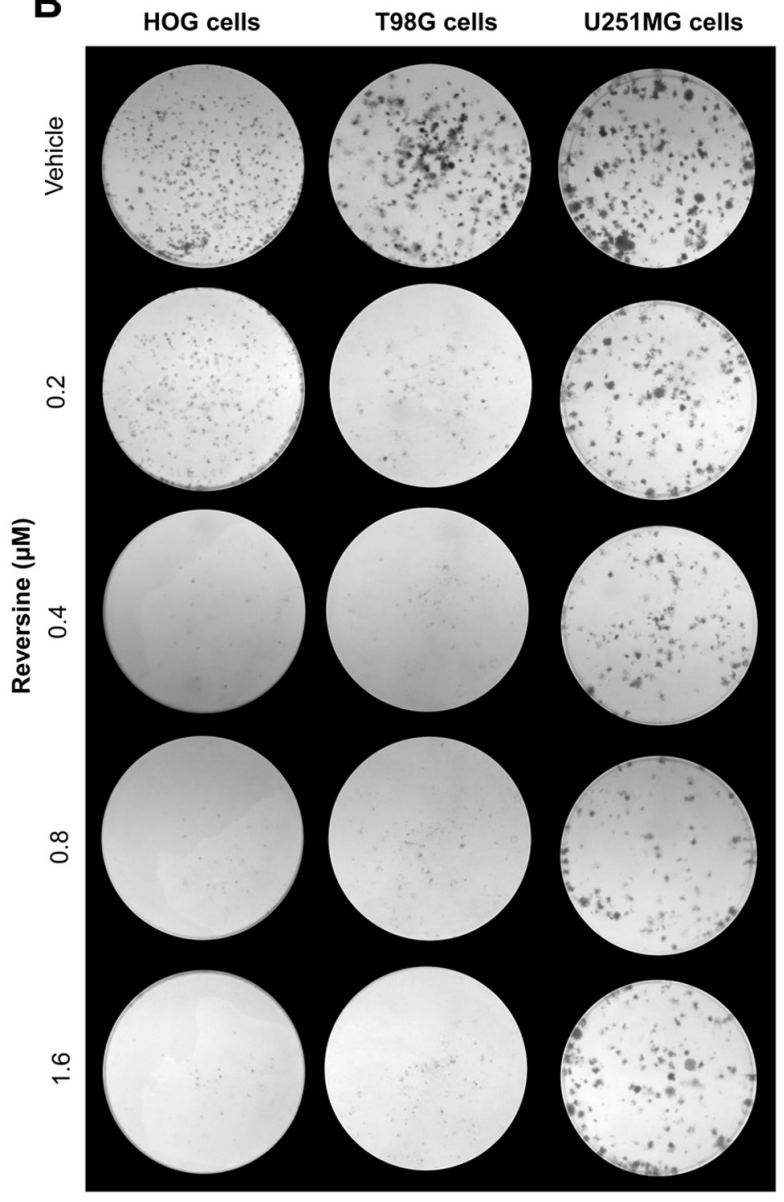

C

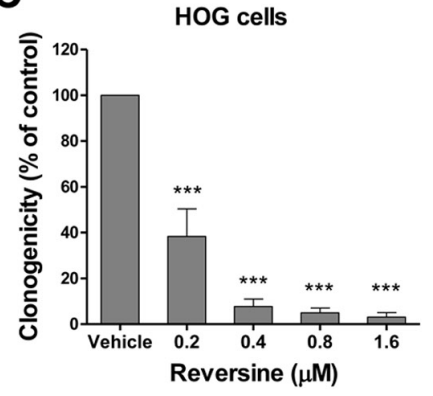

T98G cells

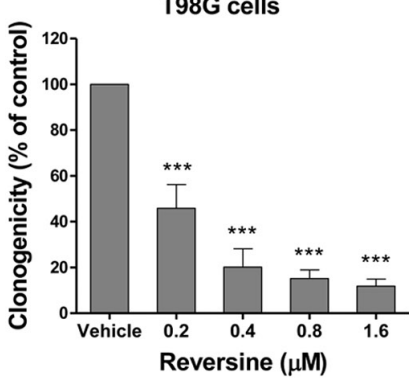

U251MG cells

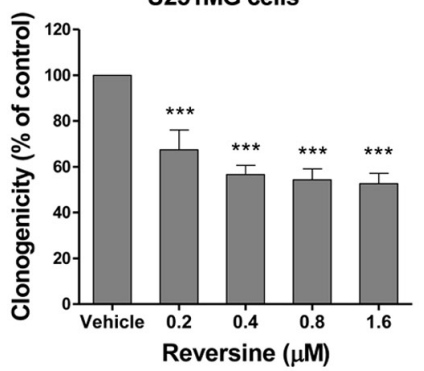

Figure 2. Reduction of cell viability and clonogenicity by reversine in glioma cells. (A) Dose- and time-response cytotoxicity analyzed by the sulforhodamine B (SRB) assay for HOG, T98G and U251MG cells treated with vehicle (DMSO) or graded concentrations of reversine (0.4, 0.8, 1.6, 3.1, 6.3, 12.5, 25 and $50 \mu \mathrm{M}$ ) for 24, 48 and $72 \mathrm{~h}$. Values are expressed as the percentage of viable cells for each condition relative to vehicle-treated cells. Results are shown as mean \pm SD of at least 3 independent experiments. (B) Colony formation after reversine exposure for $24 \mathrm{~h}$ and placement in drug-free media for an additional 10-15 days. Representative images of colony formation after vehicle or reversine $(0.2,0.4,0.8$, and $1.6 \mu \mathrm{M})$ treatment are illustrated. (C) Bar graph represents mean $\pm \mathrm{SD}$ of relative number of colonies (\% of control). ${ }^{*} \mathrm{P}<0.05,{ }^{* *} \mathrm{P}<0.01$ and ${ }^{* * *} \mathrm{P}<0.001$. IC, inhibitory concentration.

To further explore the molecular findings using pharmacological tools, Z-VAD-FMK (pan-caspase inhibitor) (30), venetoclax (selective BCL2 inhibitor) (31) and obatoclax (mimetic BH3) (32) were used in combination with reversine in glioma cells. Z-VAD-FMK treatment partially attenuated the reduction of cell viability induced by reversine (Fig. S2). Venetoclax $\left(\mathrm{IC}_{50}\right.$ ranged from 6.1 to $13.6 \mu \mathrm{M}$ ) and obatoclax $\left(\mathrm{IC}_{50}\right.$ ranged from 0.10 to $\left.0.21 \mu \mathrm{M}\right)$ treatment reduced glioma cell viability and potentiated the antineoplastic effects of reversine in glioma cells (Fig. S3). These data indicated that caspase-mediated apoptosis contributes to the reversine-induced reduction of cell viability in glioma cells, as previously reported for other solid tumors (i.e. colorectal cancer and renal carcinoma) $(28,29)$ and adds new insights into BCL2-related processes in this context.

\section{Discussion}

In the present study, the cellular and molecular effects of reversine were investigated in glioma cells. Reversine has emerged as a potential anticancer agent and its antineoplastic effects have already been reported for hematological neoplasms (28,33-35), oral squamous cell carcinoma (36), thyroid cancer $(37,38)$, breast cancer $(12,39)$, cervical carcinoma (40), non-small cell lung cancer (41), urothelial carcinoma (42), renal carcinoma (43), colon carcinoma $(14,44)$, osteosarcoma (45) and others (15). The main mechanisms of cell death attributed to the reduction in cell viability induced by reversine are mitotic catastrophe, apoptosis and autophagy $(33,36,39)$. In solid tumors, the $\mathrm{IC}_{50}$ for reversine ranges from $>1$ to $20 \mu \mathrm{M}$ and hence the data obtained related to glioma in the present study $\left(\mathrm{IC}_{50}>0.4-13 \mu \mathrm{M}\right)$ suggested that reversine is potent for this type of tumor. From a molecular point of view, reversine acts as a selective multikinase inhibitor for AURKA, AURKB, JNK and MPS1 $(14,28,33,46)$.

A functional role and a prognostic relevance for the expression of aurora kinases in gliomas have been identified, providing evidence that these proteins are potential therapeutic targets in this disease $(18,25)$. In gliomas, AURKA expression is high in advanced stages of the disease and its high expression is associated with proliferation (e.g. Ki-67) and angiogenesis (e.g. HIF1 $\alpha$ ) markers and predicts a worse prognosis (25). Similarly, AURKB expression is high in glioblastomas, is related to chemoresistance to temozolomide and negatively impacts the 
A
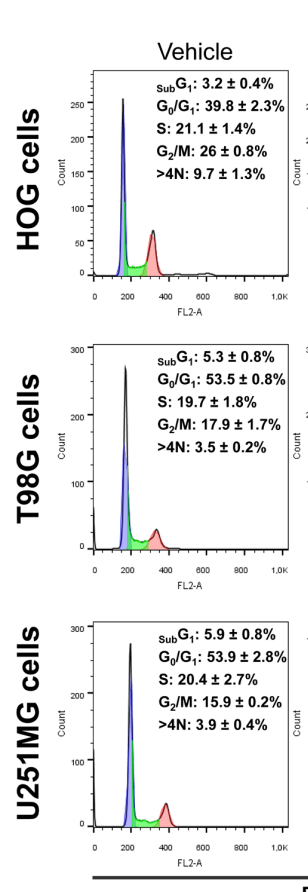

Reversine $(\mu \mathrm{M})$
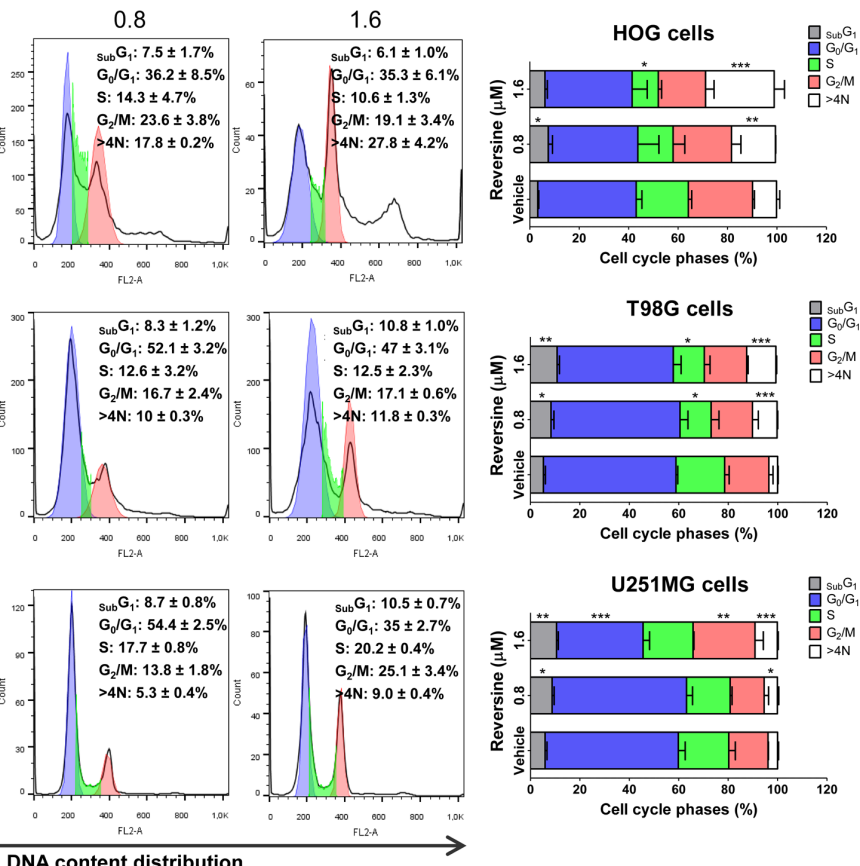

B
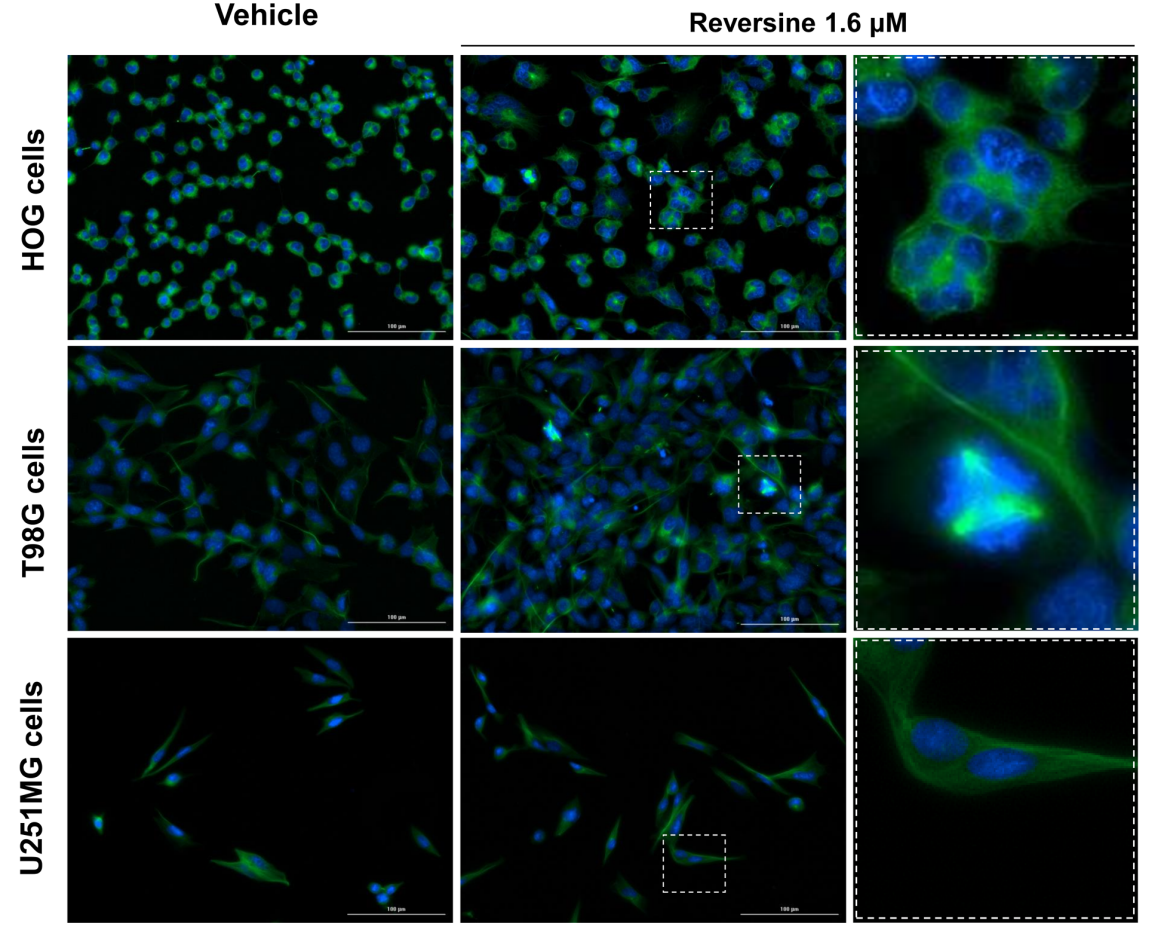

Figure 3. Reversine induced mitotic aberrations and polyploidy in glioma cells. (A) Cell cycle progression was determined by PI staining and flow cytometry in HOG, T98G and U251MG cells treated with vehicle (DMSO) or 0.8 and $1.6 \mu \mathrm{M}$ of reversine for $24 \mathrm{~h}$. A representative histogram for each condition is illustrated. Bar graphs represent the mean $\pm S D$ of the percent of cells in ${ }_{\text {sub }} G_{1}, G_{0} / G_{1}, S, G_{2} / M$ and $>4 N$ cells for conditions from at least three independent experiments. ${ }^{*} \mathrm{P}<0.05,{ }^{* *} \mathrm{P}<0.01$ and ${ }^{* * * *} \mathrm{P}<0.001$. (B) Immunofluorescence analysis of HOG, T98G and U251MG cells treated with $1.6 \mu \mathrm{M}$ reversine or vehicle for $24 \mathrm{~h}$, displaying $\alpha$-tubulin (green) and DAPI (blue) staining. The zoomed images highlight mitotic aberrations and/or polyploidy observed upon reversine exposure. Scale bar, $100 \mu \mathrm{m}$. PI, propidium iodide.

clinical outcome (18). The genetic or pharmacological inhibition of aurora kinases reduces tumor viability and growth and increases sensitivity to chemotherapy and radiotherapy in vitro and in vivo models of glioblastoma $(18,47,48)$. For instance, the combined treatment of VX680 (an aurora kinase inhibitor) and radiation enhances the efficacy of radiotherapy by targeting radioresistant cells in mice xenografted with human glioma (47).
In the present study, HOG cells, which had the highest AURKB levels, also demonstrated the greatest sensitivity to reversine. AURKB serves an essential role in cytokinesis (16), which corroborates with the significant increase in polyploidy observed in HOG cells after exposure to reversine in the present study. Similarly, T98G cells, which had the highest AURKA levels in the present study, demonstrated multiple mitotic 
A

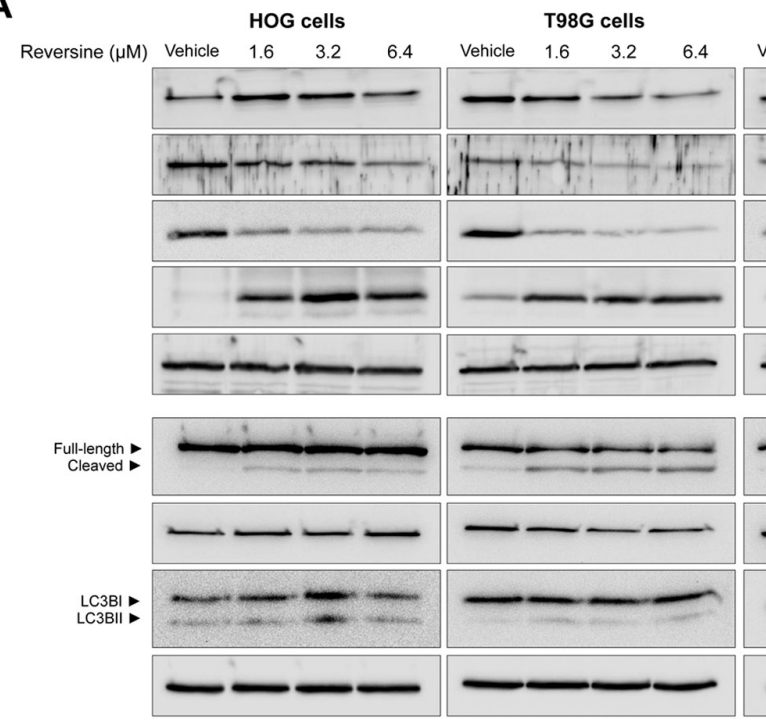

U251MG cells

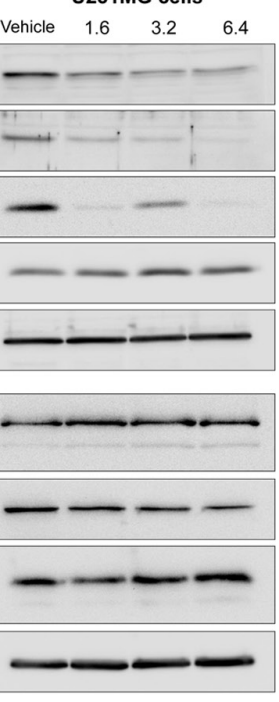

B

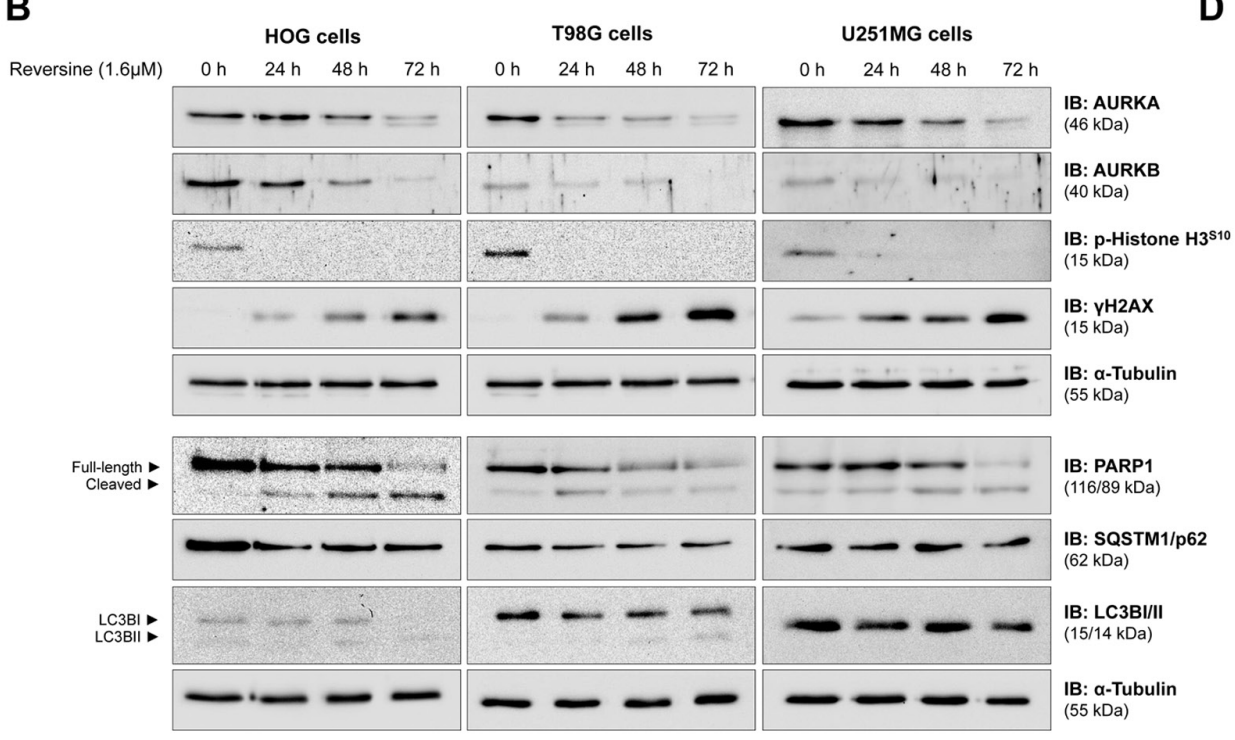

C

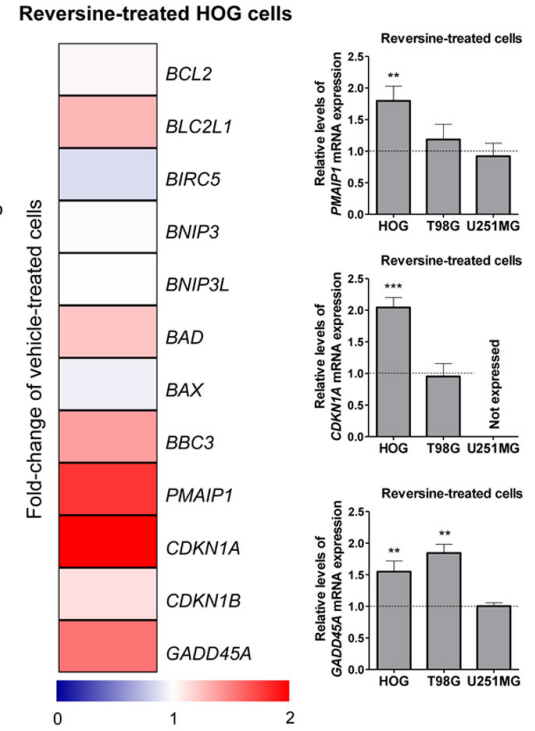

D
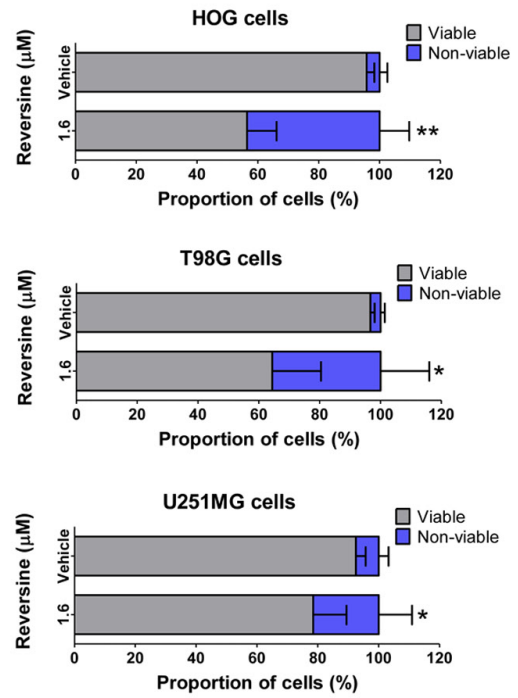

Figure 4. Reversine triggered apoptosis and DNA damage markers in glioma cells. Western blot analysis for AURKA, AURKB, p-histone H3 ${ }^{\text {s10 }}, \gamma \mathrm{H} 2 \mathrm{AX}, \mathrm{PARP} 1$ (total and cleaved), LC3BI/II and SQSTM1/p62 in total cell extracts from HOG, T98G and U251MG cells treated with (A) vehicle (DMSO) or graded concentrations of reversine (vehicle, 1.6, 3.2 or $6.4 \mu \mathrm{M}$ ) for $24 \mathrm{~h}$ or (B) graded time of exposure $(24,48$ and $72 \mathrm{~h}$ ) to reversine at $1.6 \mu \mathrm{M}$. Membranes were reprobed with the antibody for the detection of $\alpha$-tubulin. (C) Heatmap illustrates the RT-qPCR analysis of BCL2, BCL2L1, BIRC5, BNIP3, BNIP3L, BAD, BAX, BBC3, PMAIP1, CDKN1A, CDKN1B and GADD45A gene expression in HOG cells upon treatment with reversine $(1.6 \mu \mathrm{M} ;$ mean, $\mathrm{n}=4)$ for $24 \mathrm{~h}$. The data are represented as the fold-change of vehicle-treated HOG cells and down and upregulated genes are shown by blue and red, respectively. Bar graph represents mean \pm SD of the fold-change of vehicle-treated cells (dotted line) for PMAIP1, CDKN1A and GADD45A in HOG, T98G, and U251MG cell lines upon reversine exposure for $24 \mathrm{~h}$. ${ }^{* *} \mathrm{P}<0.1$ and ${ }^{* * *} \mathrm{P}<0.001$. (D) Trypan blue exclusion dye assay in HOG, T98G, and U251MG cells upon vehicle or $1.6 \mu \mathrm{M}$ reversine treatment for $72 \mathrm{~h}$. Bar graph represents relative mean \pm SD of viable (gray) and non-viable (blue) cells. " $\mathrm{P}<0.05$ and ${ }^{* * *} \mathrm{P}<0.01$. p, phosphorylated; RT-q, reverse transcription-quantitative; AURKA, aurora kinase A; AURKB, aurora kinase B; $\gamma \mathrm{H} 2 \mathrm{AX}$, phosphorylated histone 2AX; PARP1, poly(ADP-ribose) polymerase 1; SQSTM1/p62, sequestosome 1; LC3BII, microtubule associated protein 1 light chain 3 beta, BCL2, BCL2 apoptosis regulator; BCL2L1, BCL2 like 1; BIRC5, baculoviral IAP repeat containing 5; BNIP3, BCL2 interacting protein 3; BNIP3L, BCL2 interacting protein 3 like; BAD, BCL2 associated agonist of cell death; BAX, BCL2 associated X, apoptosis regulator; BBC3, BCL2 binding component 3; PMAIP1, phorbol-12-myristate-13-acetate-induced protein 1; CDKN1A, cyclin dependent kinase inhibitor 1A; CDKN1B, cyclin dependent kinase inhibitor 1B; GADD45A, growth arrest and DNA damage inducible gene 45 alpha.

aberrations including the formation of cells with multiple mitotic spindles. AURKA serves a central role in the organization of spindle orientation (16), which corroborates with the morphological findings in T98G cells in the present study. The lower sensitivity of U251MG cells, which also expressed lower AURKA and AURKB levels in the present study, suggested that the expression of aurora kinases may serve as a marker of response to reversine, which could facilitate the use of this drug in the context of personalized medicine.
Despite the recent finding that reversine induces autophagy in several cancer models $(35,36,38,41,42)$, in glioma cells in the present study no consistent modulation was observed in autophagy markers, LC3B, or STSQM1/p62 with reversine exposure. Autophagy is a complex and conserved process that acts as a double-edged sword, promoting cell death or serving as a mechanism of resistance to apoptosis (49). Hence, in glioma cells in the present study, the absence of autophagy modulation observed could explain the greater sensitivity to reversine 
because mitotic catastrophe followed by apoptosis, seems to be the main mechanism in the reduction of cell viability.

Among the modulated genes upon reversine exposure in HOG cells, the increase in cell cycle arrest markers $(C D K N 1 A$ and $G A D D 45 A)$ and the pro-apoptotic gene responsive to DNA damage (PMAIPl) were observed in the present study. The CDKN1A and GADD45A genes encode a cyclin-dependent kinase inhibitor and a sensor of oncogenic stress, respectively, which are both important for cell cycle progression and the maintenance of centrosome stability (50-52). The PMAIP1 gene (also known as NOXA) is a pro-apoptotic member of the BCL2 protein family, which acts as a $\mathrm{BH} 3$-only protein and is involved in the intrinsic apoptosis pathway (53). Notably, in the present study, the combination of reversine with venetoclax (selective BCL2 inhibitor) or obatoclax (mimetic BH3) demonstrated potentiating effects in reducing cell viability in glioma cells. Together, these data provided additional evidence for the reversine-modulated molecular network and new potential drug response markers.

Despite new insights from a cellular and molecular perspective on the reversine action in glioma models, a limitation of the present study is that the experiments were only carried out in 2D cell line models. Future studies using 3D culture, primary glioma cells or animal models are therefore required and may provide solid evidence about the antineoplastic potential of reversine for the treatment of gliomas.

In conclusion, based on the findings of the present study, reversine potently induces mitotic catastrophe and apoptosis in glioma cells. The exploratory molecular analysis suggested that the expression of aurora kinases as well as the induction of genes responsive to DNA damage, CDKN1A, PMAIP1 and $G A D D 45 A$ may be related to an improved anticancer response to reversine in glioma cells. The preclinical findings of the present study highlighted that reversine may be a putative novel drug in the antineoplastic arsenal against gliomas.

\section{Acknowledgements}

The authors thank Prof. Regina Pekelmann Markus (University of São Paulo, São Paulo, Brazil) for providing the cell lines used in the present study.

\section{Funding}

This study was supported by grants (grant nos. 2019/23864-7, 2018/19372-9 and 2015/17177-6) from the São Paulo Research Foundation (FAPESP) and grant no. 402587/2016-2 from the Conselho Nacional de Desenvolvimento Científico e Tecnológico (CNPq). This study was financed in part by the Coordenação de Aperfeiçoamento de Pessoal de Nível Superior - Brasil (CAPES) - Finance Code 001.

\section{Availability of data and materials}

The datasets used and/or analyzed during the present study are available from the corresponding author upon reasonable request.

\section{Authors' contributions}

$\mathrm{CH}$ and $\mathrm{KL}$ designed, performed and analyzed the experiments and prepared the manuscript. BODA, LBLDM, KGDF and LCF participated in the experiments and analysis. LVCL provided input, participated in the interpretation of the manuscript data and prepared the manuscript. JMN supervised and participated in the overall design of study and the experiments and analyses and prepared the manuscript. LVCL and JMN confirmed the authenticity of all the raw data. All authors have read and approved the final manuscript.

\section{Ethics approval and consent to participate}

Not applicable.

\section{Patient consent for publication}

Not applicable.

\section{Competing interests}

The authors declare that they have no competing interests.

\section{References}

1. Ostrom QT, Patil N, Cioffi G, Waite K, Kruchko C and Barnholtz-Sloan JS: CBTRUS Statistical Report: Primary Brain and Other Central Nervous System Tumors Diagnosed in the United States in 2013-2017. Neuro Oncol 22 (Suppl 2): iv1-iv96, 2020.

2. Louis DN, Perry A, Reifenberger G, von Deimling A, FigarellaBranger D, Cavenee WK, Ohgaki H, Wiestler OD, Kleihues P and Ellison DW: The 2016 World Health Organization Classification of Tumors of the Central Nervous System: A summary. Acta Neuropathol 131: 803-820, 2016.

3. Straube C, Schmidt-Graf F, Wiestler B, Zimmer C, Meyer B and Combs SE: The algorithms of adjuvant therapy in gliomas and their effect on survival. J Neurosurg Sci 63: 179-186, 2019.

4. Goldbrunner R, Ruge M, Kocher M, Lucas CW, Galldiks N and Grau S: The Treatment of Gliomas in Adulthood. Dtsch Arztebl Int 115: 356-364, 2018.

5. Gittleman H, Boscia A, Ostrom QT, Truitt G, Fritz Y, Kruchko C and Barnholtz-Sloan JS: Survivorship in adults with malignant brain and other central nervous system tumor from 2000-2014. Neuro Oncol 20 (Suppl 7): vii6-vii16, 2018.

6. Brennan CW, Verhaak RG, McKenna A, Campos B, Noushmehr H, Salama SR, Zheng S, Chakravarty D, Sanborn JZ, Berman SH, et al; TCGA Research Network: The somatic genomic landscape of glioblastoma. Cell 155: 462-477, 2013.

7. Stupp R, Mason WP, van den Bent MJ, Weller M, Fisher B, Taphoorn MJ, Belanger K, Brandes AA, Marosi C, Bogdahn U, et al; European Organisation for Research and Treatment of Cancer Brain Tumor and Radiotherapy Groups; National Cancer Institute of Canada Clinical Trials Group: Radiotherapy plus concomitant and adjuvant temozolomide for glioblastoma. N Engl J Med 352: 987-996, 2005.

8. Ali MY, Oliva CR, Noman ASM, Allen BG, Goswami PC, Zakharia Y, Monga V, Spitz DR, Buatti JM and Griguer CE: Radioresistance in Glioblastoma and the Development of Radiosensitizers. Cancers (Basel) 12: 12, 2020.

9. Gilbert MR, Dignam JJ, Armstrong TS, Wefel JS, Blumenthal DT, Vogelbaum MA, Colman H, Chakravarti A, Pugh S, Won M, et al: A randomized trial of bevacizumab for newly diagnosed glioblastoma. N Engl J Med 370: 699-708, 2014.

10. Fisher JP and Adamson DC: Current FDA-approved therapies for high-grade malignant Gliomas. Biomedicines 9: 9, 2021

11. Brat DJ, Verhaak RG, Aldape KD, Yung WK, Salama SR, Cooper LA, Rheinbay E, Miller CR, Vitucci M, Morozova O, et al; Cancer Genome Atlas Research Network: Comprehensive, integrative genomic analysis of diffuse lower-grade gliomas. N Engl J Med 372: 2481-2498, 2015.

12. Huang D, Huang Y, Huang Z, Weng J, Zhang S and Gu W: Relation of AURKB over-expression to low survival rate in BCRA and reversine-modulated aurora $\mathrm{B}$ kinase in breast cancer cell lines. Cancer Cell Int 19: 166, 2019. 
13. Song HK, Noh EM, Kim JM, You YO, Kwon KB and Lee YR: Reversine inhibits MMP-3, IL-6 and IL-8 expression through suppression of ROS and JNK/AP-1 activation in interleukin-1 $\beta$-stimulated human gingival fibroblasts. Arch Oral Biol 108: 104530, 2019.

14. Jemaà M, Abassi Y, Kifagi C, Fezai M, Daams R, Lang F and Massoumi R: Reversine inhibits Colon Carcinoma Cell Migration by Targeting JNK1. Sci Rep 8: 11821, 2018.

15. Piccoli M, Ghiroldi A, Monasky MM, Cirillo F, Ciconte G, Pappone C and Anastasia L: Reversine: A synthetic purine with a dual activity as a cell dedifferentiating agent and a selective anticancer drug. Curr Med Chem 27: 3448-3462, 2020.

16. Willems E, Dedobbeleer M, Digregorio M, Lombard A, Lumapat PN and Rogister B: The functional diversity of Aurora kinases: A comprehensive review. Cell Div 13: 7, 2018.

17. Diekema DS: Is taller really better? Growth hormone therapy in short children. Perspect Biol Med 34: 109-123, 1990.

18. Alafate W, Wang M, Zuo J, Wu W, Sun L, Liu C, Xie W and Wang J: Targeting Aurora kinase B attenuates chemoresistance in glioblastoma via a synergistic manner with temozolomide. Pathol Res Pract 215: 152617, 2019.

19. Tang A, Gao K, Chu L, Zhang R, Yang J and Zheng J: Aurora kinases: Novel therapy targets in cancers. Oncotarget 8: 23937-23954, 2017.

20. Marumoto T, Zhang D and Saya H: Aurora-A - a guardian of poles. Nat Rev Cancer 5: 42-50, 2005.

21. Steigemann P, Wurzenberger C, Schmitz MH, Held M, Guizetti J, Maar S and Gerlich DW: Aurora B-mediated abscission checkpoint protects against tetraploidization. Cell 136: 473-484, 2009.

22. Pérez Fidalgo JA, Roda D, Roselló S, Rodríguez-Braun E and Cervantes A: Aurora kinase inhibitors: A new class of drugs targeting the regulatory mitotic system. Clin Transl Oncol 11: 787-798, 2009

23. Libertini S, Abagnale A, Passaro C, Botta G and Portella G: Aurora A and B kinases - targets of novel anticancer drugs. Recent Patents Anticancer Drug Discov 5: 219-241, 2010.

24. Borisa AC and Bhatt HG: A comprehensive review on Aurora kinase: Small molecule inhibitors and clinical trial studies. Eur J Med Chem 140: 1-19, 2017.

25. Lehman NL, O'Donnell JP, Whiteley LJ, Stapp RT, Lehman TD, Roszka KM, Schultz LR, Williams CJ, Mikkelsen T, Brown SL, et al: Aurora A is differentially expressed in gliomas, is associated with patient survival in glioblastoma and is a potential chemotherapeutic target in gliomas. Cell Cycle 11: 489-502, 2012

26. Livak KJ and Schmittgen TD: Analysis of relative gene expression data using real-time quantitative PCR and the 2(-Delta Delta C(T)) method. Methods 25: 402-408, 2001.

27. Saeed AI, Sharov V, White J, Li J, Liang W, Bhagabati N, Braisted J, Klapa M, Currier T, Thiagarajan M, et al: TM4: A free, open-source system for microarray data management and analysis. Biotechniques 34: 374-378, 2003.

28. Lima K, Carlos JAEG, Alves-Paiva RM, Vicari HP, Souza Santos FP, Hamerschlak N, Costa-Lotufo LV, Traina F and Machado-Neto JA: Reversine exhibits antineoplastic activity in JAK2V617F-positive myeloproliferative neoplasms. Sci Rep 9: $9895,2019$.

29. Hama S, Matsuura S, Tauchi H, Yamasaki F, Kajiwara Y, Arita K, Yoshioka H, Heike Y, Mandai K and Kurisu K: p16 Gene transfer increases cell killing with abnormal nucleation after ionising radiation in glioma cells. Br J Cancer 89: 1802-1811, 2003.

30. Van Noorden CJ: The history of Z-VAD-FMK, a tool for understanding the significance of caspase inhibition. Acta Histochem 103 : 241-251,2001.

31. Souers AJ, Leverson JD, Boghaert ER, Ackler SL, Catron ND, Chen J, Dayton BD, Ding H, Enschede SH, Fairbrother WJ, et al ABT-199, a potent and selective BCL-2 inhibitor, achieves antitumor activity while sparing platelets. Nat Med 19: 202-208, 2013.

32. Nguyen M, Marcellus RC, Roulston A, Watson M, Serfass L, Murthy Madiraju SR, Goulet D, Viallet J, Bélec L, Billot X, et al: Small molecule obatoclax (GX15-070) antagonizes MCL-1 and overcomes MCL-1-mediated resistance to apoptosis. Proc Natl Acad Sci USA 104: 19512-19517, 2007.

33. D'Alise AM, Amabile G, Iovino M, Di Giorgio FP, Bartiromo M, Sessa F, Villa F, Musacchio A and Cortese R: Reversine, a novel Aurora kinases inhibitor, inhibits colony formation of human acute myeloid leukemia cells. Mol Cancer Ther 7: 1140-1149, 2008 .
34. Rodrigues Alves AP, Machado-Neto JA, Scheucher PS, Paiva HH, Simões BP, Rego EM and Traina F: Reversine triggers mitotic catastrophe and apoptosis in K562 cells. Leuk Res 48: 26-31, 2016

35. Carlos J, Lima K, Coelho-Silva JL, de Melo Alves-Paiva R, Moreno NC, Vicari HP, de Souza Santos FP, Hamerschlak N, Costa-Lotufo LV, Traina F, et al: Reversine exerts cytotoxic effects through multiple cell death mechanisms in acute lymphoblastic leukemia. Cell Oncol (Dordr) 43: 1191-1201, 2020.

36. Lee YR, Wu WC, Ji WT, Chen JY, Cheng YP, Chiang MK and Chen HR: Reversine suppresses oral squamous cell carcinoma via cell cycle arrest and concomitantly apoptosis and autophagy. J Biomed Sci 19: 9, 2012.

37. Hua SC, Chang TC, Chen HR, Lu CH, Liu YW, Chen SH, Yu HI, Chang YP and Lee YR: Reversine, a 2,6-disubstituted purine, as an anti-cancer agent in differentiated and undifferentiated thyroid cancer cells. Pharm Res 29: 1990-2005, 2012.

38. Lu CH, Liu YW, Hua SC, Yu HI, Chang YP and Lee YR: Autophagy induction of reversine on human follicular thyroid cancer cells. Biomed Pharmacother 66: 642-647, 2012.

39. Kuo CH, Lu YC, Tseng YS, Shi CS, Chen SH, Chen PT, Wu FL, Chang YP and Lee YR: Reversine induces cell cycle arrest, polyploidy, and apoptosis in human breast cancer cells. Breast Cancer 21: 358-369, 2014

40. Qin HX, Yang J, Cui HK, Li SP, Zhang W, Ding XL and Xia YH Synergistic antitumor activity of reversine combined with aspirin in cervical carcinoma in vitro and in vivo. Cytotechnology 65: 643-653, 2013

41. Lu YC, Lee YR, Liao JD, Lin CY, Chen YY, Chen PT and Tseng YS: Reversine induced multinucleated cells, cell apoptosis and autophagy in human non-small cell lung cancer cells. PLoS One 11: e0158587, 2016

42. Fang CY, Chen JS, Chang SK and Shen CH: Reversine induces autophagic cell death through the AMP-activated protein kinase pathway in urothelial carcinoma cells. Anticancer Drugs 29: 29-39, 2018.

43. Cheng L, Wang H, Guo K, Wang Z, Zhang Z, Shen C, Chen L and Lin J: Reversine, a substituted purine, exerts an inhibitive effect on human renal carcinoma cells via induction of cell apoptosis and polyploidy. OncoTargets Ther 11: 1025-1035, 2018.

44. Park YL, Ha SY, Park SY, Choi JH, Jung MW, Myung DS, Kim HS and Joo YE: Reversine induces cell cycle arrest and apoptosis via upregulation of the Fas and DR5 signaling pathways in human colorectal cancer cells. Int J Oncol 54: 1875-1883, 2019.

45. Kim JS, Cho IA, Kang KR, Lim H, Kim TH, Yu SK, Kim HJ, Lee SA, Moon SM, Chun HS, et al: Reversine induces caspase-dependent apoptosis of human osteosarcoma cells through extrinsic and intrinsic apoptotic signaling pathways. Genes Genomics 41: 657-665, 2019.

46. Hiruma Y, Koch A, Dharadhar S, Joosten RP and Perrakis A: Structural basis of reversine selectivity in inhibiting Mps1 more potently than aurora B kinase. Proteins 84: 1761-1766, 2016.

47. 47. Li N, Maly DJ, Chanthery YH, Sirkis DW, Nakamura JL, Berger MS, James CD, Shokat KM, Weiss WA and Persson AI: Radiotherapy followed by aurora kinase inhibition targets tumor-propagating cells in human glioblastoma. Mol Cancer Ther 14: 419-428, 2015

48. Hong X, O'Donnell JP, Salazar CR, Van Brocklyn JR, Barnett KD, Pearl DK, deCarvalho AC, Ecsedy JA, Brown SL, Mikkelsen T, et al: The selective Aurora-A kinase inhibitor MLN8237 (alisertib) potently inhibits proliferation of glioblastoma neurosphere tumor stem-like cells and potentiates the effects of temozolomide and ionizing radiation. Cancer Chemother Pharmacol 73: 983-990, 2014.

49. Galluzzi L, Pietrocola F, Bravo-San Pedro JM, Amaravadi RK, Baehrecke EH, Cecconi F, Codogno P, Debnath J, Gewirtz DA, Karantza V, et al: Autophagy in malignant transformation and cancer progression. EMBO J 34: 856-880, 2015.

50. Xiao BD, Zhao YJ, Jia XY, Wu J, Wang YG and Huang F: Multifaceted p21 in carcinogenesis, stemness of tumor and tumor therapy. World J Stem Cells 12: 481-487, 2020.

51. Salvador JM, Brown-Clay JD and Fornace AJ Jr: Gadd45 in stress signaling, cell cycle control, and apoptosis. Adv Exp Med Biol 793: 1-19, 2013

52. Liebermann DA, Tront JS, ShaX,Mukherjee K, Mohamed-Hadley A and Hoffman B: Gadd45 stress sensors in malignancy and leukemia. Crit Rev Oncog 16: 129-140, 2011.

53. Morsi RZ, Hage-Sleiman R, Kobeissy H and Dbaibo G: Noxa: Role in cancer pathogenesis and treatment. Curr Cancer Drug Targets 18: 914-928, 2018.

This work is licensed under a Creative Commons Attribution-NonCommercial-NoDerivatives 4.0 International (CC BY-NC-ND 4.0) License. 